\title{
Health-related quality of life and psychological distress among cancer survivors in Southeast Asia: results from a longitudinal study in eight low- and middle-income countries
}

The ACTION Study Group ${ }^{1,2}$

\begin{abstract}
Background: A better understanding of health-related quality of life (HRQoL) and psychological distress in cancer survivors can raise awareness, promote the development of policies in cancer survivorship care, and facilitate better targeted use of limited resources in low- and middle-income countries (LMICs). The main objectives of this paper were therefore to assess HRQoL and the prevalence of psychological distress amongst cancer survivors in Southeast Asia and identify risk factors of these outcomes.

Methods: The ACTION study was a longitudinal study in eight LMICs in Southeast Asia with 5249 first time cancer survivors followed up at 1 year after diagnosis. HRQoL was assessed using the EORTC QLQ-C30 and EQ-5D. Psychological distress (anxiety and depression) was assessed using the Hospital Anxiety and Depression Scale. General linear models and multiple logistic regression were used to identify independent predictors of HRQoL and psychological distress.

Results: One year after diagnosis, the mean EORTC QLQ-C30 global health score for survivors was 66.2 out of 100 (SD 22.0), the mean index score on the EQ-5D was 0.74 (SD 0.23), 37\% of survivors had at least mild levels of anxiety, and $46 \%$ showed at least mild levels of depression. Poorest HRQoL and highest prevalence of anxiety and depression were seen in patients with lung cancer and lymphomas, while highest scores and least psychological distress were seen in female patients with breast and cervical cancer. The most significant predictor of poor HRQOL and psychological distress outcomes was cancer stage at diagnosis. Age, co-morbidities, treatment, and several socioeconomic factors were associated with HRQoL and psychological distress.

Conclusions: Cancer survivors in LMICs in Southeast Asia have impaired HRQOL and substantial proportions have psychological distress. Patients with advanced cancer stages at diagnosis and those in a poor socioeconomic position were most at risk of such poor outcomes. Supportive interventions for cancer patients that address wider aspects of patient wellbeing are needed, as well as policies that address financial and other barriers to timely treatment.
\end{abstract}

Keywords: Health-related quality of life, Psychological distress, Cancer, Survivorship, Low- and middle-income countries, Southeast Asia, Observational study

\footnotetext{
* Correspondence: merel.kimman@mumc.nl

1The George Institute for Global Health, University of Sydney, Level 10, King George V Building, 83-117 Missenden Rd, Camperdown, NSW 2050, Australia ${ }^{2}$ Department of Clinical Epidemiology and Medical Technology Assessment, Maastricht University Medical Centre, Minderbroedersberg 4-6, Maastricht 6211 LK, The Netherlands
} 


\section{Background}

Cancer is the world's second leading cause of death and a major cause of disability. In 2013, an estimated 8.2 million individuals died of cancer, equating to $15 \%$ of all deaths globally [1]. While cancer survival rates are improving in high-income countries, cancer mortality rates are particularly high in low- and middle-income countries (LMICs), largely because of delays in diagnosis leading to presentation with advanced disease [2]. Breast cancer survival rates, for instance, range from $80 \%$ or higher in North America, Sweden and Japan to around $60 \%$ in middleincome countries and below $40 \%$ in low-income countries [3]. In addition, cancer affects populations in LMICs at relatively young ages, resulting in long periods of illhealth, great loss of productivity, and premature deaths $[2,4]$. The burden of cancer continues to increase because of the ageing and growth of the population alongside increasing levels of cancer-causing behaviors such as smoking, physical inactivity, and unhealthy dietary habits [2]. Thus, cancer threatens health and economic development in LMICs and requires urgent attention [5-8].

The ACTION study was a longitudinal study of 9513 newly diagnosed cancer patients in eight LMICs in Southeast Asia, set up to prospectively assess the impact of cancer on households' economic wellbeing and health [9]. Results of the study reported thus far have demonstrated that families living in Southeast Asia struggled to manage the costs associated with cancer care; over half the households faced catastrophic out-of-pocket payments (defined as spending more than $30 \%$ of household income for cancer-related costs) in the year after diagnosis $[10,11]$.

In addition to economic outcomes, key outcomes considered were health-related quality of life (HRQoL) and psychological distress 1 year after diagnosis [9]. While treatment has generally been completed a year after diagnosis, the cancer burden may still be significant due to short- and long-term sequelae that impair HRQoL $[12,13]$. Cancer survivors are at increased risk of cancerrelated fatigue and psychological symptoms [14-19]. Poor health is an important barrier to get back to work or take up activities of daily living after treatment [20, 21], thereby putting individuals and families at risk of impoverishment. However, few studies have been conducted in LMICs, and awareness of health issues affecting cancer survivors is still low [22, 23]. A better understanding of HRQoL and psychological distress in cancer survivors can raise awareness, promote the development of policies in cancer survivorship care, and facilitate better targeted use of limited resources [8].

The main objectives of this study were to assess HRQoL and the prevalence of psychological distress amongst cancer survivors in LMICs in Southeast Asia, 1 year after diagnosis. Secondary objectives were to identify demographic, clinical and socioeconomic predictors of poor HRQoL and psychological distress.

\section{Methods}

\section{Setting and participants}

The ACTION study was a prospective longitudinal study in which cancer patients from eight LMICs of ASEAN (Cambodia, Indonesia, Laos, Malaysia, Myanmar, Philippines, Thailand and Vietnam) were invited to participate. Detailed methods have been published previously [9]. In brief, 9513 first-time cancer patients were consecutively recruited from 47 sites, of which more than 95\% were public hospitals. Participants, aged 18 years and over, were interviewed by study staff at baseline (within 12 weeks after clinical diagnosis) and at 3 and 12 months after diagnosis. One year after diagnosis, $29 \%(n=1993)$ of the initial study population had died and $24 \% \quad(n=2271)$ were lost to follow-up. The remaining 5249 survivors were contactable at 12 months and were included in this report.

The ACTION study was approved by the University of Sydney Human Research Ethics Committee. Approvals from local institutional ethics committees and other regional or national regulatory bodies were obtained prior to the initiation of the study in any site (Additional file 1). Written informed consent, complying with local, regional, and national requirements, was obtained from all participants prior to entry into the study.

\section{Patient-reported health outcomes}

Cancer-specific HRQoL was assessed by the European Organisation for Research and Treatment of Cancer (EORTC) Quality of Life Questionnaire (QLQ) C30 (version 3.0). Official translations were available for all countries except Laos and Cambodia [24]. The following were assessed: global health status, role function, cognitive function, physical function, emotional function, social function, fatigue, nausea and vomiting, pain, dyspnea, insomnia, appetite, constipation, and diarrhea. Scores are presented on a linear scale of 0 to 100 . Higher scores correspond to better HRQoL in the function and global health scales, whereas higher scores in symptom scales and items represent more problems with symptoms [25].

Generic HRQoL was assessed using the EuroQol-5 dimensions questionnaire (EQ-5D) [26], which comprises five items relating to problems in mobility, selfcare, usual activities, pain and discomfort, and anxiety and depression. The EQ-5D index provides a valuation of HRQoL in which full health is scored at 1 , and death is 0 [27]. Official translations were provided by the EuroQoL group for all countries except Laos and Cambodia, covering $96 \%$ of the study population. 
Psychological distress was measured using the Hospital Anxiety and Depression Scale (HADS), which measures generalized anxiety and depression experienced during the past week with two subscales: anxiety (HADS-A) and depression (HADS-D) [28]. The HADS is a selfreport instrument and has been widely used in cancer patients [29]. A cut-off of $\geq 8$ on the HADS-D scale and $\geq 9$ on the HADS-A was used to indicate cases of least mild depression and anxiety, respectively [29]. Official translations were available for Indonesia, Malaysia, Philippines and Thailand, covering $63 \%$ of the study population.

In cases where a formal translation was not available, questionnaires were translated using forward-translation and back-translation following WHO guidelines for the process of translation of questionnaires [30].

\section{Predictor variables}

We considered a range of demographic, socioeconomic and clinical variables as putative predictors of $\mathrm{HRQOL}$ and psychological distress. The demographic and socioeconomic variables considered were collected through self-reported questionnaires and relate to the time of entry to the study (baseline). Demographic variables considered were age, sex, marital status, and country of residence. Socioeconomic variables considered were household income (grouped into low $(0-75 \%$ of mean national income), middle (75-125\%) and high income $(>125 \%)$ ), economic hardship (whether in the 12 months previous to baseline they were unable to make necessary household payments or needed assistance to do so [31]), employment status (paid work), health insurance status, and highest level of education attained. Clinical variables obtained from medical records at baseline comprised cancer site, cancer stage at diagnosis (clinical TNM classification), and pre-existing chronic conditions. Treatment modality was ascertained at the end of study (12 months after baseline).

\section{Statistical analyses}

Descriptive statistics were used to report the distribution of demographic, socioeconomic and clinical characteristics of the full study population, and separately by sex. The distribution of HRQoL scores and prevalence of anxiety and depression at 12 months was determined for the study population, the most common cancer types (those with more than 200 cases), and other potential predictors of these outcomes. Evidence-based guidelines for the interpretation of differences in EQ-5D and QLQC30 scores were used [32, 33]. For example, an observed mean difference of $<4$ points on the QLQ-C30 global health scale was considered trivial and unlikely to have clinical relevance [34]. General linear models for HRQoL endpoints and multiple logistic regression for anxiety and depression were used to determine the association between predictor variables and study outcomes. To limit the number of tests and its associated increased likelihood of a type I error occurring, multivariable analyses were conducted for selected outcomes; global health, physical function, emotional function, fatigue, and pain. These outcomes are hypothesized to be most distinctive for the long-term health of different subgroups of cancer patients [21]. Stratified analyses explored the impact of predictor variables across the most common cancer types.

\section{Results \\ Study sample}

Characteristics of the 5249 survivors followed-up at 12 months are shown in Table 1; Additional file 2: Table S1A details the characteristics by sex. The mean age of the study population was 52 years (range, 18-100) and 69\% were female. Almost half of the participants $(n=2365$, 45\%) were from lower middle-income countries (Laos, Indonesia, Vietnam, and the Philippines), followed by upper middle-income countries (Malaysia and Thailand; $n=2199,42 \%)$ and low-income countries (Cambodia and Myanmar; $n=685,13 \%$ ).

The most common cancer types were breast (32\%), cervix (11\%), mouth and pharynx (11\%), colon and rectum (11\%), and lymphomas (5\%). Among patients with available data on cancer stage $(\mathrm{n}=3172), 14 \%$ presented with stage I, 38\% with stage II, 31\% with stage III, and $17 \%$ with stage IV cancers, whereas hematological cancers were diagnosed in 436 patients (8\%). Fifty-six percent of participants had surgery as part of treatment, $68 \%$ had chemotherapy and $46 \%$ had radiotherapy (not mutually exclusive).

In females, cancer of the breast (45\%) and cervix (17\%) were most common. Among males, mouth $(23 \%)$ and colorectal (19\%) cancer were most common. Of female participants, $35 \%$ presented with stage I or II cancer compared to only $18 \%$ of males.

\section{Patient-reported health outcomes}

A year after diagnosis, the mean global health score for survivors was 66.2 (SD 22.0) on the QLQ-C30 (Table 2). Scores on function scales ranged from 73.7 (SD 26.6) for social functioning, to 79.0 (SD 22.8) for physical function and 86.2 (SD 20.7) for cognitive functioning. In terms of symptoms, highest scores (i.e., more symptoms) were reported for fatigue (24.7), pain (21.4), and insomnia (21.2). The mean index score on the EQ-5D was 0.74 (SD 0.23). In terms of psychological distress, a year after diagnosis, anxiety was seen in $37 \%$ of survivors and depression in $46 \%$.

Poorer outcomes, i.e., lowest HRQoL scores and highest symptom scores, were consistently seen in lung cancer and lymphoma patients (Fig. 1a-c, Additional file 2: 
Table 1 Demographic, socioeconomic, and clinical characteristics of the study population $(n=5249)$

\begin{tabular}{lll}
\hline Characteristic All & \\
\cline { 2 - 3 } & $\mathrm{N}$ & $\%$ \\
\hline
\end{tabular}

Age, years

$\begin{array}{lll}<45 & 1569 & 30 \\ 45-54 & 1577 & 30 \\ 55-64 & 1369 & 26 \\ \geq 65 & 732 & 14 \\ \text { Missing } & 2 & <\end{array}$

Sex

Male

Female

1618

3631

Marital status

Married

Unmarried

$$
4047
$$

1202

Level of education

$$
\begin{aligned}
& \text { 0-6 years (primary) } \\
& 7-12 \text { years (secondary) } \\
& >12 \text { years (tertiary) }
\end{aligned}
$$$$
1932 \quad 37
$$

1148

Country of residence

Cambodia
Indonesia
Laos
Malaysia
Myanmar
Philippines
Thailand
Vietnam

$131 \quad 3$

$673 \quad 13$

56

1361

554

458

838

1178

Household income (of mean national income)

Low
Med
High
Do not know/missing

1643

1048

1815

743

Health insurance status

Yes

None

2249

2999

Missing

1

Experienced economic hardship in the year before diagnosis

$\begin{array}{lll}\text { Yes } & 2643 & 50 \\ \text { No } & 2605 & 50 \\ \text { Missing } & 1 & <1\end{array}$

Paid work (patient level) before diagnosis (self-employed or for a wage)

Yes

No
$2481-47$

\begin{tabular}{|c|c|c|}
\hline \multicolumn{3}{|l|}{ Cancer site } \\
\hline Mouth and pharynx & 571 & 11 \\
\hline Esophagus & 49 & $<1$ \\
\hline Stomach & 143 & 3 \\
\hline Colon and rectum & 552 & 11 \\
\hline Liver & 26 & $<1$ \\
\hline Pancreas & 26 & $<1$ \\
\hline Trachea, bronchus and lung & 226 & 4 \\
\hline Melanoma & 18 & $<1$ \\
\hline Breast & 1654 & 32 \\
\hline Cervix & 598 & 11 \\
\hline Uterus & 127 & 2 \\
\hline Ovary & 123 & 2 \\
\hline Prostate & 27 & $<1$ \\
\hline Bladder & 20 & $<1$ \\
\hline Lymphomas and multiple myeloma & 241 & 5 \\
\hline Leukemia & 195 & 4 \\
\hline Other malignant neoplasms & 617 & 12 \\
\hline Missing & 36 & $<1$ \\
\hline \multicolumn{3}{|l|}{ Cancer (TNM) stage at diagnosis } \\
\hline Stage I & 437 & 8 \\
\hline Stage II & 1190 & 23 \\
\hline Stage III & 984 & 19 \\
\hline Stage IV & 561 & 11 \\
\hline None (hematological cancers) & 436 & 8 \\
\hline Missing & 1641 & 31 \\
\hline \multicolumn{3}{|l|}{ Treatment $^{a}$} \\
\hline Surgery & 2931 & 56 \\
\hline Radiotherapy & 2438 & 46 \\
\hline Chemotherapy & 3550 & 68 \\
\hline Hormonal therapy & 496 & 9 \\
\hline \multicolumn{3}{|c|}{ Pre-existing chronic conditions (as reported in medical files) } \\
\hline 0 & 4032 & 77 \\
\hline 1 & 839 & 16 \\
\hline$\geq 2$ & 352 & 7 \\
\hline Missing & 26 & $<1$ \\
\hline
\end{tabular}

$\begin{array}{ll}2481 & 47 \\ 2768 & 53\end{array}$

Table 1 Demographic, socioeconomic, and clinical characteristics of the study population $(n=5249)$ (Continued)

${ }^{a}$ Categories are not mutually exclusive since most patients received a combination of treatments

Table S2A). Mean QLQ-C30 global health scores were respectively 56.5 (SD 23.2) and 52.8 (SD 27.2) for lung and lymphoma, compared to 74.2 (SD 17.7) and 69.7 (SD 19.4) for cancers of the cervix and breast. Similarly, the proportion of patients reporting moderate or severe problems on the EQ-5D domains was highest for lung cancer and lymphomas (Fig. 1d). The EQ-5D index scores for lung 
Table 2 Health-related quality of life (HRQOL) and psychological distress 1 year after diagnosis

\begin{tabular}{lll}
\hline & \multicolumn{2}{l}{ All cancers $(n=5249)$} \\
\hline HRQoL & & \\
Cancer-specific HRQoL (EORTC QLQ-C30) & Mean & 22.0 \\
Global health & 66.2 & 22.8 \\
Physical function & 79.0 & 24.8 \\
Emotional function & 76.2 & 28.8 \\
Role function & 74.8 & 20.7 \\
Cognitive function & 86.2 & 26.6 \\
Social function & 73.7 & 25.2 \\
Fatigue & 24.7 & 18.9 \\
Nausea/vomiting & 10.7 & 25.4 \\
Pain & 21.4 & 22.8 \\
Dyspnea & 13.9 & 27.5 \\
Insomnia & 21.2 & 27.9 \\
Appetite loss & 20.0 & 21.4 \\
Constipation & 11.3 & 17.1 \\
Diarrhea & 7.8 & \\
Generic HRQoL (EQ-5D) & & 0.23 \\
Index score & 0.74 & \\
Psychological distress & $\mathrm{N}$ & \\
HADS-A: Anxiety & 1933 & \\
HADS-D: Depression & 2394 & \\
\hline HADS Hospital Anxiety and Depression Scale & & \\
\hline & & \\
\hline
\end{tabular}

cancer and lymphomas were 0.63 (SD 0.24) and 0.69 (SD 0.24 ), respectively, compared to 0.76 (SD 0.21 ) and 0.78 (SD 0.21) for cancers of the breast and cervix, respectively. The proportion of patients with psychological distress was also highest among lung and lymphoma cancer patients; $60 \%$ of these patients report depression and anxiety was seen in 50\% of lung cancer patients and 58\% of lymphoma patients. Highest HRQoL scores, lowest symptom burden and lowest prevalence of anxiety and depression were seen in patients with cancer of the cervix.

HRQoL outcomes and psychological distress for subgroups of patients are presented in Table 3. Clinically meaningful differences in HRQoL scores (i.e., $>4$ points difference on EORTC scales) were seen between participants older than 65 years compared to those younger than 45 years (e.g., EQ-5D index of 0.67 (SD 0.25) vs. 0.76 (SD 0.22), physical function of 72.6 (SD 28.0) vs. 81.9 (SD 21.5)). Older participants also reported more anxiety (45\% vs. $36 \%)$ and depression (56\% vs. $43 \%)$ than participants younger than 45 years. Male cancer survivors reported lower HRQoL scores on the EQ-5D, the QLQ-C30 function scales, and for fatigue and pain, but mean differences are considered trivial [34]. The prevalence of anxiety (42\% vs. $35 \%)$ and depression (52\% vs.
43\%), however, is substantially higher in males than in females. The socioeconomic variables household income (low vs high), economic hardship, and not being in paid work were all associated with lower HRQoL scores, but differences were small. Nevertheless, a high income and paid work were associated with fewer cases of anxiety and depression. Health insurance was not associated with HRQoL and psychological distress.

Cancer stage at diagnosis and co-morbidities were associated with HRQoL and psychological distress. Directions were as expected; a more advanced cancer stage and more than two pre-existing chronic conditions were associated with lower HRQoL scores (all endpoints) and more cases of psychological distress.

Findings from the multivariable linear model showed that, in general, predictor variables, except treatment modalities (radiotherapy and chemotherapy), had a significant independent impact on HRQoL and psychological distress (Table 4). HRQol scores decreased, and the odds of psychological distress increased, with increasing age. Males had lower emotional function scores and higher odds of psychological distress compared to females. Other HRQoL outcomes were not affected by sex. Being married (vs. unmarried) positively impacted on physical and emotional function (QLQ-C30), but not on global health, the EQ-5D index, and psychological distress. Cancer stage at diagnosis was the strongest predictor with clinically meaningful reductions in HRQoL and psychological distress; stage IV and hematological cancers were predictive of severely impaired HRQoL (all endpoints) and the odds of having anxiety or depression. Having multiple chronic conditions was an important predictor for poor HRQoL and psychological distress. A high income (vs. low) and being in paid work positively impacted on most HRQoL outcomes and were associated with lower odds of psychological distress. Health insurance was associated with higher global health scores, but lower scores for physical function, pain and fatigue, and slightly higher odds of depression.

Multivariable models stratified by cancer type showed that stage at diagnosis was the most important predictor of HRQoL and psychological distress across breast, cervical, lung, mouth, colorectal cancer, and lymphomas (Additional file 2: Tables S4A-F). In addition, a range of socioeconomic variables were associated with HRQoL endpoints and psychological distress across these cancer types. Results of the stratified analyses must be interpreted with caution because the models (except for breast cancer) were generally underpowered and could therefore only detect the strongest predictors.

\section{Discussion}

One year after diagnosis, we identified impaired HRQoL and a prevalence of anxiety of $37 \%$ and depression of 


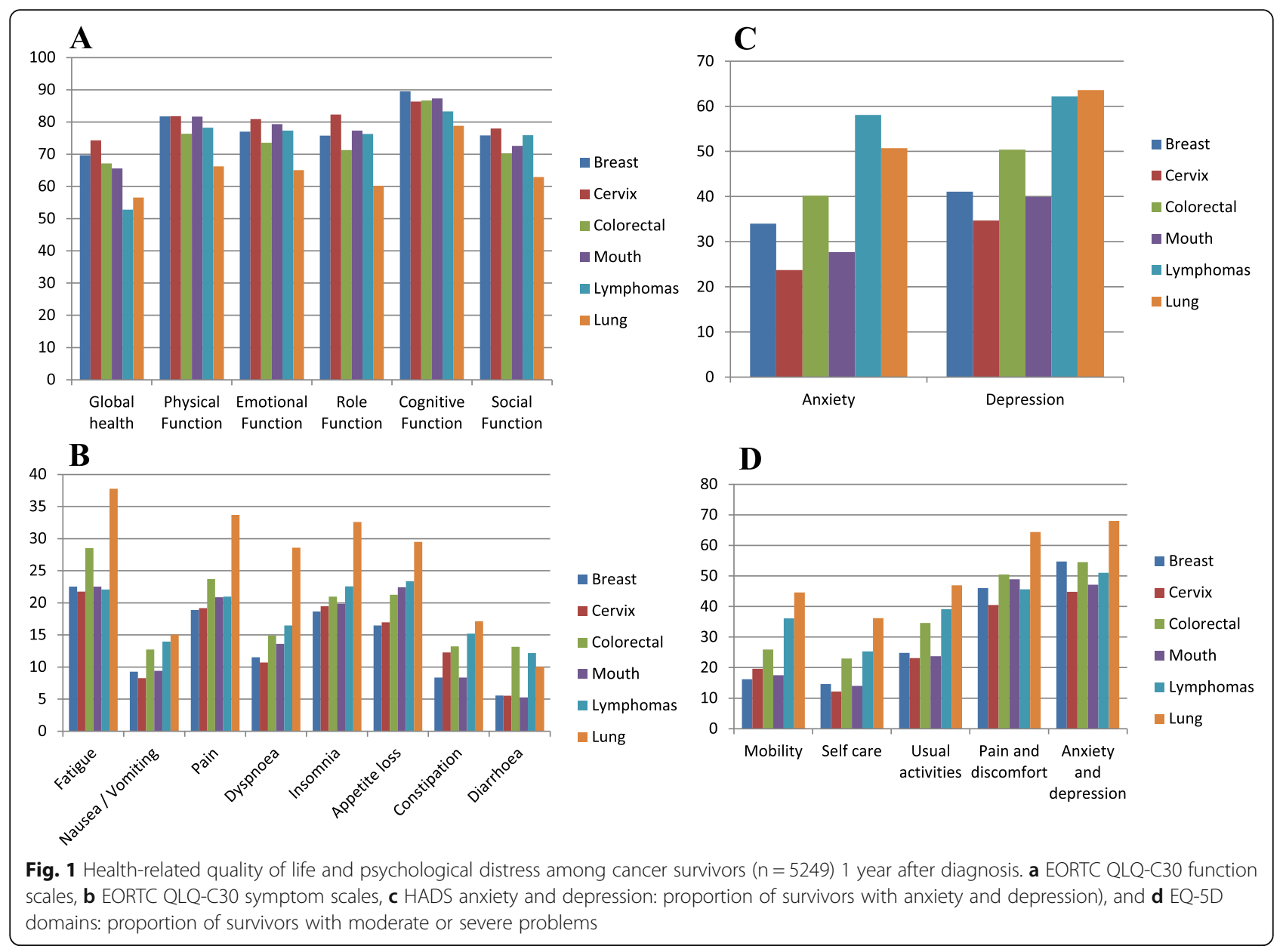

46\% amongst cancer survivors in LMICs in Southeast Asia. Differences in HRQoL and psychological distress were observed based on age, sex, household income, cancer type, and stage at diagnosis. In general, older patients, males, patients with lung cancer or lymphomas, an advanced stage at diagnosis, low income status, and those not in paid work reported lowest HRQoL scores and were most likely to report anxiety and depression. Female patients with cancer of the breast and cervix showed the most favorable outcomes reflecting a better prognosis for these type of cancers [2]. An advanced cancer stage at diagnosis was the strongest independent predictor of poor HRQoL outcomes and psychological distress. In addition, increasing age, having multiple chronic conditions, and several socioeconomic variables were identified as being independently associated with poor outcomes.

Inevitably, comparison of HRQoL and psychological distress with earlier studies is rough due to the varying settings, cancer types, and measures used. We are aware of few studies among cancer survivors in Southeast Asia or other LMICs $[19,35]$. Most research on cancer survivorship has been conducted in high-income settings where patients were more likely to receive a timely diagnosis, optimal treatment, follow-up, and survivorship care. Survival rates, therefore, differ drastically between countries but, regardless of setting, many cancer survivors experience symptom burden, loss of HRQoL, and (at least mild) psychological distress in the first year after treatment $[12,13,36,37]$. Cancer stage is widely recognized as an important clinical determinant of HRQoL in cancer survivors [12, 19, 37-42]. A diagnosis of lung cancer and having comorbid conditions are also associated with a high symptom burden and low HRQoL [12, 13, 36, 37]. In both low- and high-income settings, socioeconomic disparity in cancer survivors has been associated with poor HRQoL [12, 13, 35, 42-45] and psychological distress $[46,47]$. Possible explanations may be poorer recognition of cancer symptoms and more barriers to access appropriate and timely healthcare services by patients with low socioeconomic status [48]. Patients with a poor socioeconomic position are also less likely to receive appropriate follow-up care and discuss concerns with their healthcare providers [49]. Our study has generally confirmed the relationship between poor socioeconomic position (e.g., a low household income, not being in 
Table 3 Demographic, socioeconomic, and clinical characteristics of the study population $(n=5249)$ and their associations with health-related quality of life (HRQoL) and psychological distress at 1 year after diagnosis as measured by the EORTC QLQ-C30, EQ-5D, and HADS

\begin{tabular}{|c|c|c|c|c|c|c|c|c|}
\hline & \multicolumn{6}{|l|}{ HRQoL } & \multicolumn{2}{|c|}{ Psychological distress } \\
\hline & \multirow{2}{*}{$\begin{array}{l}\text { Generic HRQoL } \\
\text { EQ-5D index }\end{array}$} & \multicolumn{5}{|c|}{ Cancer-specific HRQoL (EORTC QLQ-C30) } & \multirow{3}{*}{$\begin{array}{l}\text { Anxiety } \\
N(\%)\end{array}$} & \multirow{3}{*}{$\begin{array}{l}\text { Depression } \\
\mathrm{N}(\%)\end{array}$} \\
\hline & & Physical function & Emotional function & Global health & Pain & Fatigue & & \\
\hline & Mean (SD) & Mean (SD) & Mean (SD) & Mean (SD) & Mean (SD) & Mean (SD) & & \\
\hline \multicolumn{9}{|l|}{ Age group, years } \\
\hline$<45$ & $0.76(0.22)$ & $81.9(21.5)$ & $77.8(24.0)$ & $67.0(23.0)$ & $19.2(24.1)$ & $21.6(24.0)$ & $570(36)$ & $678(43)$ \\
\hline $45-54$ & $0.75(0.22)$ & $80.9(21.9)$ & $76.7(24.2)$ & $67.5(21.1)$ & $20.7(25.7)$ & $23.5(24.6)$ & $513(33)$ & $663(42)$ \\
\hline $55-64$ & $0.73(0.23)$ & $77.9(22.1)$ & $75.8(24.4)$ & $65.9(21.0)$ & $22.1(24.9)$ & $26.1(24.9)$ & $519(38)$ & $644(47)$ \\
\hline$\geq 65$ & $0.67(0.25)$ & $70.5(26.1)$ & $72.6(28.0)$ & $62.6(23.3)$ & $31.4(28.3)$ & $31.4(28.3)$ & $330(45)$ & $408(56)$ \\
\hline \multicolumn{9}{|l|}{ Sex } \\
\hline Female & $0.75(0.22)$ & $80.1(21.7)$ & $76.8(24.4)$ & $66.2(18.1)$ & $20.2(24.5)$ & $23.9(24.8)$ & $1262(35)$ & $1560(43)$ \\
\hline Male & $0.71(0.24)$ & $76.5(24.8)$ & $75.0(25.5)$ & $62.3(20.0)$ & $24.1(27.0)$ & $26.6(26.0)$ & $671(42)$ & $834(52)$ \\
\hline \multicolumn{9}{|l|}{ Marital status } \\
\hline Married & $0.74(0.23)$ & $79.2(22.5)$ & $76.5(24.3)$ & $66.7(21.6)$ & $21.5(25.3)$ & $24.6(25.0)$ & $1501(37)$ & $1845(46)$ \\
\hline Not married & $0.73(0.23)$ & $78.3(23.6)$ & $75.5(26.3)$ & $64.9(23.5)$ & $21.1(25.7)$ & $24.9(26.1)$ & $432(36)$ & $549(46)$ \\
\hline \multicolumn{9}{|l|}{ Level of education } \\
\hline 0-6 years (primary) & $0.73(0.23)$ & $77.8(24.1)$ & $77.1(24.8)$ & $68.1(21.6)$ & $21.5(26.1)$ & $24.2(25.7)$ & $641(33)$ & 849 (44) \\
\hline $7-12$ years (secondary) & $0.74(0.23)$ & $79.1(21.8)$ & $75.4(24.2)$ & $64.3(21.4)$ & $22.1(24.8)$ & $25.7(24.7)$ & $908(42)$ & $1088(50)$ \\
\hline$>12$ years (tertiary) & $0.75(0.22)$ & $80.8(22.2)$ & $76.3(25.8)$ & $66.8(23.5)$ & $19.9(25.2)$ & $23.7(25.4)$ & 384 (33) & $457(40)$ \\
\hline \multicolumn{9}{|l|}{ Household income } \\
\hline Low (0-75\%) & $0.71(0.23)$ & $76.5(24.9)$ & $74.0(25.8)$ & $64.9(23.2)$ & $23.3(27.0)$ & $25.4(26.4)$ & $712(43)$ & $818(50)$ \\
\hline Med (75-125\%) & $0.72(0.23)$ & $78.3(21.8)$ & $76.0(24.3)$ & $65.1(22.1)$ & $21.5(24.9)$ & $23.6(24.2)$ & $420(40)$ & $526(50)$ \\
\hline High (> 125\%) & $0.78(0.22)$ & $81.6(21.2)$ & $78.0(24.4)$ & $67.1(20.7)$ & $18.7(23.8)$ & $24.0(24.5)$ & $510(28)$ & $685(38)$ \\
\hline \multicolumn{9}{|l|}{ Health insurance } \\
\hline Yes & $0.75(0.22)$ & $78.6(24.2)$ & $76.9(24.8)$ & $68.0(21.4)$ & $22.7(26.3)$ & $25.9(26.1)$ & $813(36)$ & $1022(46)$ \\
\hline No & $0.73(0.23)$ & 79.3 (21.6) & $75.7(24.8)$ & $64.9(22.4)$ & $20.4(24.6)$ & $23.8(24.5)$ & $1120(38)$ & $1372(46)$ \\
\hline \multicolumn{9}{|l|}{ Economic hardship } \\
\hline Yes & $0.73(0.23)$ & $77.1(24.9)$ & $75.2(25.9)$ & $67.8(22.0)$ & $23.6(27.5)$ & $26.6(27.1)$ & 949 (36) & $1217(46)$ \\
\hline No & $0.75(0.22)$ & $80.9(20.2)$ & $77.3(23.6)$ & $64.7(22.0)$ & $19.2(22.8)$ & $22.8(23.0)$ & $984(38)$ & $1177(45)$ \\
\hline \multicolumn{9}{|l|}{ Paid work } \\
\hline Yes & $0.75(0.22)$ & $80.9(22.2)$ & $77.0(24.9)$ & $67.3(21.8)$ & $19.5(25.1)$ & $22.7(24.8)$ & 787 (32) & $996(40)$ \\
\hline No & $0.72(0.23)$ & $77.2(23.2)$ & $75.5(24.7)$ & $65.3(22.2)$ & $23.1(25.6)$ & $26.5(25.5)$ & $1146(42)$ & $1398(51)$ \\
\hline \multicolumn{9}{|l|}{ Cancer stage at diagnosis } \\
\hline Stage I & $0.81(0.20)$ & $85.7(15.8)$ & $82.3(18.9)$ & $74.2(18.3)$ & $12.5(18.0)$ & $16.6(19.5)$ & $99(23)$ & $141(32)$ \\
\hline Stage ॥ & $0.79(0.21)$ & $83.6(18.6)$ & $79.9(22.8)$ & $71.5(18.9)$ & $15.7(21.1)$ & $20.0(22.0)$ & $323(27)$ & $424(36)$ \\
\hline Stage III & $0.75(0.22)$ & $79.6(23.3)$ & $76.0(25.3)$ & $69.0(21.6)$ & $20.4(26.1)$ & $24.0(25.6)$ & $296(30)$ & $400(41)$ \\
\hline Stage IV & $0.65(0.24)$ & $69.8(29.0)$ & $63.4(34.7)$ & $57.0(23.8)$ & $32.6(32.0)$ & $36.6(32.3)$ & 265 (47) & 327 (58) \\
\hline None (hematological & $0.67(0.23)$ & 77.4 (18.6) & 77.9 (18.6) & $44.7(26.8)$ & $21.1(21.0)$ & $22.1(19.6)$ & 308 (71) & $313(72)$ \\
\hline
\end{tabular}


Table 3 Demographic, socioeconomic, and clinical characteristics of the study population $(n=5249)$ and their associations with health-related quality of life (HRQoL) and psychological distress at 1 year after diagnosis as measured by the EORTC QLQ-C30, EQ-5D, and HADS (Continued)

\begin{tabular}{|c|c|c|c|c|c|c|c|c|}
\hline \multicolumn{9}{|l|}{ Treatment $^{\mathrm{b}}$} \\
\hline Surgery & $0.78(0.22)$ & $82.1(21.2)$ & $78.7(25.2)$ & $69.9(20.5)$ & $17.9(24.5)$ & $22.1(25.3)$ & $1051(36)$ & $1051(36)$ \\
\hline No surgery & $0.68(0.23)$ & $74.8(24.1)$ & $72.9(24.1)$ & $61.4(23.2)$ & $25.7(25.8)$ & $27.9(24.9)$ & $1123(51)$ & $1322(60)$ \\
\hline Radiotherapy & $0.73(0.22)$ & $78.6(22.5)$ & $76.1(24.4)$ & $67.0(21.7)$ & $20.1(24.9)$ & $25.3(25.0)$ & 881 (36) & $1123(46)$ \\
\hline No radiotherapy & $0.74(0.23)$ & $79.2(22.9)$ & $76.2(25.3)$ & $65.5(22.5)$ & $22.5(25.8)$ & $24.0(25.5)$ & $1026(38)$ & $1248(46)$ \\
\hline Chemotherapy & $0.73(0.23)$ & $78.6(22.7)$ & $75.2(25.2)$ & $65.0(22.9)$ & $21.7(25.6)$ & $25.3(25.6)$ & $1330(38)$ & $1652(47)$ \\
\hline No chemotherapy & $0.76(0.23)$ & $79.7(23.0)$ & $78.4(23.9)$ & $69.0(20.2)$ & $20.2(24.7)$ & $23.1(24.6)$ & $580(36)$ & $732(45)$ \\
\hline \multicolumn{9}{|c|}{ Pre-existing chronic conditions } \\
\hline 0 & $0.74(0.23)$ & $79.6(22.4)$ & $76.8(24.0)$ & $66.3(22.0)$ & $21.1(25.1)$ & $24.0(24.8)$ & $1503(37)$ & $1853(46)$ \\
\hline 1 & $0.74(0.23)$ & $79.0(22.8)$ & $77.2(24.7)$ & $66.5(21.7)$ & $20.4(24.8)$ & $24.2(24.9)$ & $266(32)$ & 357 (43) \\
\hline$\geq 2$ & $0.67(0.23)$ & 71.5 (25.1) & $67.5(31.7)$ & $64.8(23.7)$ & $27.5(29.5)$ & $34.6(29.3)$ & $159(45)$ & $177(50)$ \\
\hline
\end{tabular}

Index scores based on Thai tariff

${ }^{\mathrm{b}}$ Categories are not mutually exclusive since most patients received a combination of treatments

paid work, and having experienced economic hardship) and impaired HRQoL and psychological distress, with one exception; primary education only was consistently associated with better study outcomes. While the absence of an association between education and HRQoL has been reported in certain cancer types and countries $[36,50]$, few studies find this inverse relationship between education and HRQoL [51]. To rule this out as a chance finding, this observation warrants further investigation. Another notable finding was that patients with health insurance were not necessarily better off than those without. These results, however, need to be interpreted with caution as we did not have data on benefit packages provided by the various health insurance schemes and associated processes of care. For example, Malaysia has achieved universal coverage that includes cancer care, but healthcare is provided through public health facilities that may have long waiting times [52].

Our study has a number of limitations. First, participation in the study was voluntary and, as such, the proportion of cases observed for individual cancers were not representations of population incidences. Clinicians responsible for enrolling patients into the study appear to have under-recruited those with the most virulent types of cancer such as lung and liver cancers. Second, by one year, $23 \%$ of the original study population had died and $24 \%$ were lost to follow-up. The high loss to follow-up is unfortunate, but not surprising, and may have introduced response bias. It is plausible that patients with poor HRQoL after treatment may have been less interested or too ill to continue participation; patients who completed the 12 months follow-up were more likely to have stage I or II cancer (Additional file 2: Table S1B). These first two limitations may have resulted in an underestimate of HRQoL and the prevalence of psychological distress in this patient population. Third, while HRQoL and psychological distress were measured upon study entry (within 12 weeks after clinical diagnosis), and at 3 and 12 months, we did not report change scores since the first two measurements are likely to reflect the type and timing of treatment (e.g., recovery from surgery, having second line treatment or just supportive care) as opposed to underlying HRQoL, and thus changes in scores may be transient fluctuations caused by treatment course. Fourth, while widely endorsed as one of the best available measures of anxiety and depression, the use of the HADS across languages and cultures has recently been criticized, e.g., there may be an unknown influence of linguistic and cultural factors on cut-points for anxiety and depression [53]. As such, there may be concerns that items in the translated version may differ conceptually to the original version. In our study, this risk may been pronounced in approximately $36 \%$ of the sample where official translations of the original questionnaires were not available and we had to undertake our own. Results presented here regarding prevalence must therefore be interpreted with caution. Nevertheless, the HADS was used for the purpose of subgroup comparisons and correlations rather than a screening tool, and therefore results provide useful insight into groups of patients with higher prevalence of anxiety and depression as well as risk factors. Finally, it was not possible to compare mean HRQoL scores of the cancer population to scores of the general population due to the lack of reference scores for Southeast Asia.

Despite limitations, our study is unique in being observational, including a large population of cancer survivors in an LMIC setting, and using a range of well-validated measures that characterize wellbeing in cancer patients. Until now, high-quality data on the quality of life lived with cancer have been lacking in ASEAN populations. 


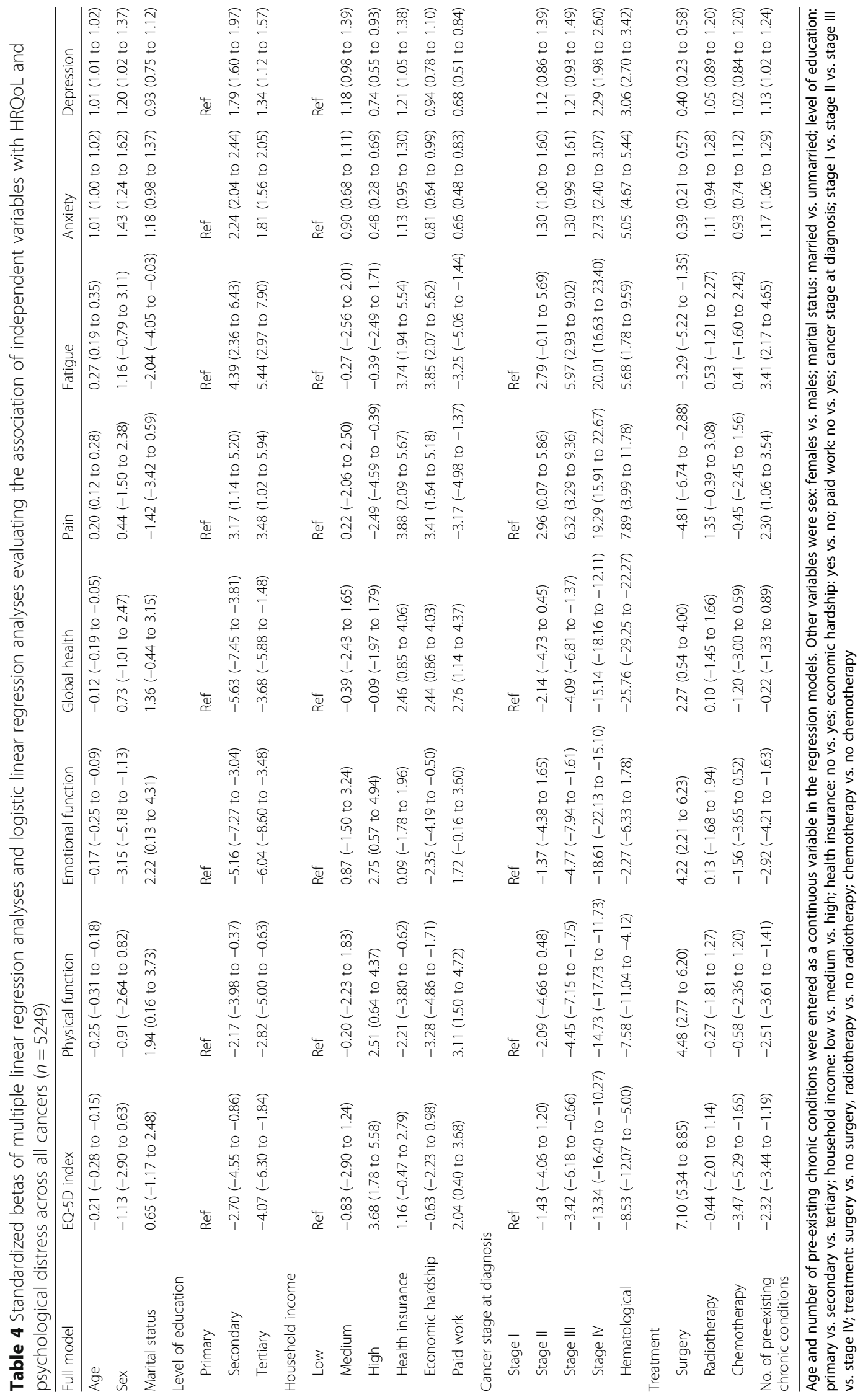


Results from this study should encourage governments in the region to take action to develop national cancer control strategies and extend national health insurance initiatives to remove barriers to early diagnosis and prompt treatment [2, 8]. Awareness education and screening for detectable cancers may result in a larger proportion of patients presenting with early stage cancers that are more likely to be able to receive curative and less invasive treatment options, leading to cost savings and a reduction in mortality [54, 55], as well as to better HRQoL and lower levels of psychological distress among survivors, as found herein. Following (early) diagnosis, governments should ensure access to appropriate and quality treatment, including medication for cancer [6]. The focus of this paper, however, is on the needs of cancer survivors. Supportive and survivorship care, i.e., the prevention and management of the adverse effects of cancer and its treatment are increasingly recognized as critical components of quality cancer care and cancer control programs. Yet, in resource-constrained health systems, survivorship care is often overlooked [56-58]. Consensus statements and recommendations have been developed, mainly for breast cancer, to illustrate how health systems in LMICs can provide appropriate cancer care, including survivorship care, taking resource constraints into account $[22,56,59]$. Most recommendations can be generalized to other cancers. First, at the health system level, appropriate follow-up care (in terms of frequency and intensity) after completion of initial treatment is needed to monitor for possible recurrences or new cancers and adverse effects of treatments [22]. Scheduled followup visits, and the name of the health professional responsible for post-treatment care, should be documented in a patient's individual care and survivorship plan [60]. This document should also include details of the patient's treatment protocol so that potential specific treatment-related complications and longterm physical side effects can be considered [56, 59]. Importantly, assessment of psychosocial needs, including depression, anxiety, emotional distress, and changes to social roles, should be part of the follow-up care provided. Health professionals need (additional) education about the recognition and management of long-term physical complications and psychosocial complications of survivorship [22]. In addition, patients must be educated on symptoms of disease recurrence and lifestyle modifications to reduce cancer risk and improve quality of life $[22,59]$. Our findings emphasize that patients in poor socioeconomic positions (e.g., low income, unemployed) and patients with late-stage cancers are at highest risk for poor HRQoL and psychological distress and therefore policies are needed to address the financial burden of treatment, including the expansion of national insurance programs and other social safety nets to offset the indirect costs incurred by patients and their families. Survivorship interventions should address wide aspects of wellbeing and are ideally implemented as part of routinely offered programs of care. Governments and research organizations should encourage this type of cancer (survivorship) research and accelerate the translation of research findings into clinical and public health practice [6].

\section{Conclusions}

This study provides valuable insight into the cancer burden in terms of HRQoL and psychological distress and risk factors for poor outcomes in low- and middle-income settings. Improving cancer awareness, early detection, prompt treatment, and appropriate survivorship care are the major public health and clinical approaches to improve the health and wellbeing of cancer survivors. Importantly, this study demonstrates that supportive interventions for cancer patients that address wider aspects of patient wellbeing are needed, including government initiatives to address the economic burden associated with treatment. Results can be used to support policies geared towards survivorship care and inform research evaluating supportive interventions.

\section{Additional files}

Additional file 1: Overview approvals local ethics boards ACTION Study. (DOCX $15 \mathrm{~kb}$ )

Additional file 2: Table S1A. Demographic, socioeconomic and clinical characteristics of the study population by sex $(n=5249)$. Table S1B. Baseline demographic, socioeconomic, and clinical characteristics of the study population ( $n=5249)$ and non-responders at 12 months $(n=2271)$. Table S2A. Health-related quality of life (HRQoL) and psychological distress 1 year after diagnosis. Presented for the most common cancer sites (more than 200 cases). Table S4A. Standardized betas of multiple linear regression analyses and logistic linear regression analyses evaluating the association of independent variables with HRQOL and psychological distress, for breast cancer patients $(N=1654)$. Table S4B. Standardized betas of multiple linear regression analyses and logistic linear regression analyses evaluating the association of independent variables with HRQOL and psychological distress, for cervix cancer patients $(n=598)$. Table S4C. Standardized betas of multiple linear regression analyses and logistic linear regression analyses evaluating the association of independent variables with HRQoL and psychological distress, for mouth and pharynx cancer patients $(n=571)$. Table S4D. Standardized betas of multiple linear regression analyses and logistic linear regression analyses evaluating the association of independent variables with $\mathrm{HRQOL}$ and psychological distress, for colorectal cancer patients $(n=552)$. Table S4E. Standardized betas of multiple linear regression analyses and logistic linear regression analyses evaluating the association of independent variables with HRQoL and psychological distress, for lung cancer patients $(n=226)$. Table S4F. Standardized betas of multiple linear regression analyses and logistic linear regression analyses evaluating the association of independent variables with HRQOL and psychological distress, for lymphoma patients $(n=241)$. (DOCX $91 \mathrm{~kb})$

\section{Abbreviations}

EORTC QLQ-C30: European Organisation for Research and Treatment of Cancer Quality of Life Questionnaire C30; EQ-5D: EuroQol-5 dimensions; HADS: Hospital Anxiety and Depression Scale; HRQoL: health-related quality of life (HRQOL); LMICs: low- and middle-income countries 


\section{Acknowledgements}

The authors wish to acknowledge the many patients and their family members who participated in this study, and physicians and other health personnel of participating sites. The Action Study Group comprises the writing committee, principal investigators and other contributors as detailed below.

Writing committee

M. L. Kimman, The George Institute for Global Health, University of Sydney, Sydney, Australia and Department of Clinical Epidemiology and Medical Technology Assessment, Maastricht University Medical Centre, Maastricht, The Netherlands; S. Jan, The George Institute for Global Health, University of Sydney, Sydney, Australia; S. A. E. Peters, The George Institute for Global Health, University of Oxford, Oxford, UK; C. H. Yip, Department of Surgery, Subang Jaya Medical Centre, Kuala Lumpur, Malaysia; C. A. Ngelangel, Section of Medical Oncology, University of the Philippines - College of Medicine, Philippine General Hospital, Manila, Philippines; N. Bhoo-Pathy, Department of Social and Preventive Medicine, Faculty of Medicine, University of Malaya, Kuala Lumpur, Malaysia and National Clinical Research Centre, Ministry of Health, Malaysia; M. Woodward, The George Institute for Global Health, University of Sydney, Sydney, Australia and The George Institute for Global Health, University of Oxford, Oxford, UK.

\section{Principal investigators}

Phetsamone Arounlangsy (Lao Cancer Center, Department of Health Care, Ministry of Health, Laos), Soe Aung (Oncology Society, Myanmar Medical Association, Yangon, Myanmar), Soledad L Balete (Section of Medical Oncology, Jose R Reyes Memorial Medical Centre, Manila, Philippines), Nirmala Bhoo-Pathy (National Clinical Research Centre, Ministry of Health, Malaysia; Faculty of Medicine, University of Malaya, Kuala Lumpur, Malaysia), Bounthaphany Bounxouei (Mahosot Hospital, Laos), Dieu Bui (K Hospital, Vietnam), Jay Datukan (Section of Medical Oncology, St Luke's Medical Centre, Quezon City, Metro Manila, Philippines), Agnes E Gorospe, (Section of Medical Oncology, St Luke's Medical Centre, Quezon City, Metro Manila, Philippines), Cheng Har Yip (University of Malaya, Kuala Lumpur, Malaysia), Yin Yin Htun (Department of Medicine, No 2 Military Hospital, Myanmar), Prasit Khopaibul (Suratthani Cancer Centre, Suratthani, Thailand), Thanut Khuayjarernpanishk (Ubonratchathani Cancer Centre, Ubonratchathani, Thailand), Thiravud Khuhaprema (National Cancer Institute of Thailand, Bangkok, Thailand), Myo Khin (Department of Medical Research, Lower Myanmar, Myanmar), David Kingston, Tawin Klinwimol (Ubonratchathani Cancer Centre, Ubonratchathani, Thailand), Somkiet Lalitwongsa (Lampang Cancer Hospital, Lampang, Thailand), Dhanoo Lawbundis (Lopburi Cancer Hospital, Lopburi, Thailand), Conrado Lola (Section of Medical Oncology, National Kidney and Transplant Institute, Quezon City, Metro Manila, Philippines), Leo Marbella (Section of Medical Oncology, National Kidney and Transplant Institute, Quezon City, Metro Manila, Philippines), Khoa Mai Trong (Bach Mai Hospital, Vietnam), Soe Oo Maung (Department of Radiotherapy, Yangon General Hospital, Yangon, Myanmar), Shu Mon (Bahosi Hospital, Myanmar), Win Pa Pa Naing (Department of Medical Research, Lower Myanmar, Myanmar), Corazon A Ngelangel (Section of Medical Oncology, University of the Philippines - College of Medicine, Philippine General Hospital, Manila, Philippines), Htun Lwin Nyein (Haematology Department, Yangon General Hospital, Yangon, Myanmar), Annielyn Beryl Ong-Cornel (Veterans Memorial Medical Centre, Quezon City, Philippines), Khin May Oo (Department of Medical Research, Lower Myanmar, Myanmar), Irisyl OrolfoReal (Section of Medical Oncology, University of the Philippines - College of Medicine, Philippine General Hospital, Manila, Philippines), Dung Pham Xuan (Oncology Hospital, Ho Chi Minh city, Vietnam), Seang Pharin (Department of Onco-Hematology, Calmette Hospital, Cambodia), Pujianto (Department of Health Policy and Administration, School of Public Health, Universitas Indonesia, Indonesia), Oudayvone Rattanavong (Mahosot Hospital, Laos), Kouy Samnang (Department of Oncology, Khmer-Soviet Friendship Hospital, Cambodia), Somphob Sangkittipaiboon (Lopburi Cancer Hospital, Lopburi, Thailand), Suleeporn Sangrajrang, (National Cancer Institute of Thailand, Bangkok, Thailand), Cherelina Santiago-Ferreras (Section of Medical Oncology, Veterans Memorial Medical Centre, Quezon City, Metro Manila, Philippines), San Shwe (Department of Medical Research, Lower Myanmar, Myanmar), Eav Sokha (National Cancer Centre, Calmette Hospital, Cambodia), Thanadej Sinthusake (Mahavajiralongkorn Thanyaburi Hospital, Pathumthani, Thailand), Darunee Suanplu (Suratthani Cancer Hospital, Suratthani, Thailand), Jitraporn Tanabodee (Chonburi Cancer Hospital, Chonburi, Thailand), Hasbullah Thabrany (Center for Health Economics and Policy Studies, Universitas Indonesia, Indonesia), Kitisak Thepsuwan (Chonburi Cancer Hospital, Chonburi, Thailand),
Heng Viroath (Department of Oncology, Khmer-Soviet Friendship Hospital, Cambodia), Le Le Win (Department of Medical Research, Lower Myanmar), Swe Swe Win (Department of Oral Medicine, University of Dental Medicine, Yangon, Myanmar), and Tin Moe Win (Mandalay General Hospital, Myanmar).

Other contributors

Ami Ashariati (Soetomo Hospital, Indonesia), Djumhana Atmakusuma (Cipto Mangunkusumo Hospital, Indonesia), I Made Bakta (Sanglah Hospital, Indonesia), Loan Dang Thi Kim (Oncology Hospital Ho Chi Minh city, Vietnam), Phung Dang Thi Ngoc (Oncology Hospital Ho Chi Minh city, Vietnam), Tuan Diep Bao (Oncology Hospital Ho Chi Minh city, Vietnam), Ario Djatmiko (Surabaya Oncology Hospital, Indonesia), Andi Fachruddin (Wahidin Hospital, Indonesia), Johan Kurnianda (Sardjito Hospital, Indonesia), Helen Monaghan (The George Institute for Global Health, Australia), Abdul Muthalib (Medistra Hospital, Indonesia), Trang Ngo Thuy (Bach Mai Hospital, Vietnam), Thao Nguyen Hoang, (K Hospital, Vietnam), Nga Nguyen Thi Hoai (K Hospital, Vietnam), Sonar S Panigoro (Dharmais Cancer Center Hospital, Indonesia), Huy Ph m Quang (K Hospital, Vietnam), Goh Pik Pin (National Clinical Research Centre, Malaysia), Khanh Quach Thanh (Oncology Hospital Ho Chi Minh city, Vietnam), Prih Sarnianto (Universitas Indonesia, Indonesia), Dradjat R Suardi (Hasan Sadikin Hospital, Indonesia), Shridevi Subramaniam (National Clinical Research Centre, Malaysia), Aru W Sudoyo (MRCCC Siloam Hospital, Indonesia), Khoa Tran Dang (Ha Noi Oncology Hospital, Vietnam), Ha Tran Dinh (Bach Mai Hospital, Vietnam), Catharina Suharti (Karyadi Hospital, Indonesia), and Suyatno (Adam Malik Hospital, Indonesia).

Institutions

CAMBODIA: Calmette Hospital (Phnom Penh) and Khmer-Soviet Friendship Hospital (Phnom Penh). INDONESIA: Adam Malik Hospital (Medan), Cipto Mangunkusumo Hospital (Jakarta), Dharmais Cancer Center Hospital (Jakarta), Hasan Sadikin Hospital (Bandung), Karyadi Hospital (Semarang), Sanglah Hospital (Denpasar), Sardjito Hospital (Yogyakarta), Soetomo Hospital (Surabaya), Wahidin Sudirohusodo Hospital (Makassar), and Surabaya Oncology Hospital (Surabaya). LAOS: Mahosot Hospital (Vientiane). MALAYSIA: Hospital Ampang (Ampang), Hospital Kuala Lumpur (Kuala Lumpur), Hospital Melaka (Melaka), Hospital Queen Elizabeth I (Kota Kinabalu), Hospital Raja Perempuan Zainab II (Kota Baru), Hospital Seri Manjung (Seri Manjung), Hospital Sibu (Sibu), Hospital Sultanah Aminah (Johor Bahru), Hospital Sungai Buloh (Sungai Buloh), Hospital Tengku Ampuan Rahimah (Klang), Hospital Tuanku Fauziah (Kangar), Hospital Wanita dan Kanak-Kanak Sabah (Likas), Sime Darby Medical Centre (Subang Jaya), National Clinical Research Centre (Kuala Lumpur), University Malaya Medical Centre (Kuala Lumpur), and University Malaya Specialist Centre (Kuala Lumpur). MYANMAR: Bahosi Hospital (Yangon), Mandalay General Hospital (Mandalay), No 2 Military Hospital (Yangon), University of Dental Medicine (Yangon), and Yangon General Hospital (Yangon). PHILIPPINES: Jose R Reyes Memorial Medical Centre (Manila), University of the Philippines - College of Medicine Philippine General Hospital (Manila), National Kidney and Transplant Institute (Quezon City), St Luke's Medical Centre (Quezon City), and Veterans Memorial Medical Centre (Quezon City). THAILAND: Chonburi Cancer Hospital (Chonburi), Lampang Cancer Hospital (Lampang), National Cancer Institute of Thailand (Bangkok), Lopburi Cancer Hospital (Lopburi), Mahavajiralongkorn Thanyaburi Hospital (Pathumthani), Suratthani Cancer Centre (Suratthani), and Ubonratchathani Cancer Hospital (Ubonratchathani). VIETNAM: Bach Mai Hospital (Hanoi), K Hospital (Hanoi), and Oncology Hospital Ho Chi Minh city. Executive committee

Nirmala Bhoo-Pathy, Bounthaphany Bounxouei, Gloria Cristal-Luna, Nguyen Chan Hung, Myo Khin, Thiravud Khuhaprema, Merel Kimman, David Kingston, Stephen Jan, Eav Sokha, Hasbullah Thabrany, and Mark Woodward.

\section{Funding}

This work was supported by an unrestricted educational grant from the Roche Asia Pacific Regional Office. The funder of the study had no role in study design, data analysis, data interpretation, or writing of this paper. Roche supported the data collection through recruitment of hospital sites and facilitating site investigator meetings. The authors had full access to all the data in the study and had final responsibility for the decision to submit for publication.

\section{Availability of data and material}

The datasets generated and/or analyzed during the current study are available from the corresponding author on reasonable request. 


\section{Authors' contributions}

Principal investigators assisted with the design of the questionnaires and were responsible for patient recruitment and data collection at participating sites. Other contributors assisted with data collection, patient interviews, and data entry. Contributions of members of the writing committee: MK, SJ, and MW designed the study; MK wrote the first draft; and SJ, SP, MW, NBP, CHY and CN made critical revisions to the manuscript. SP conducted the statistical analysis. All members approved the final manuscript.

\section{Competing interests}

The authors declare that they have no competing interests.

\section{Consent for publication}

Not applicable.

\section{Ethics approval and consent to participate}

The ACTION study was approved by the University of Sydney Human Research Ethics Committee. Approvals from local institutional ethics committees and other regional or national regulatory bodies were obtained prior to the initiation of the study in any site (Additional file 1). Written informed consent, complying with local, regional and national requirements, was obtained from all participants prior to entry into the study.

\section{Received: 25 August 2016 Accepted: 8 December 2016}

\section{Published online: 13 January 2017}

\section{References}

1. GBD 2013 Mortality and Causes of Death Collaborators. Global, regional, and national age-sex specific all-cause and cause-specific mortality for 240 causes of death, 1990-2013: a systematic analysis for the Global Burden of Disease Study 2013. Lancet. 2015;385(9963):117-71.

2. Stewart BW, Wild CP. World Cancer Report 2014. International Agency for Research on Cancer: Lyon; 2014.

3. Coleman MP, Quaresma M, Berrino F, Lutz JM, De Angelis R, Capocaccia R, Baili P, Rachet B, Gatta G, Hakulinen T, et al. Cancer survival in five continents: a worldwide population-based study (CONCORD). Lancet Oncol. 2008:9(8):730-56.

4. Kimman $M$, Norman $R$, Jan $S$, Kingston $D$, Woodward $M$. The burden of cancer in member countries of the Association of Southeast Asian Nations (ASEAN). Asian Pac J Cancer Prev. 2012;13(2):411-20.

5. World Health Organization. Global Status Report on Noncommunicable Diseases 2014. Geneva: WHO; 2014.

6. Woodward M. A consensus plan for action to improve access to cancer care in the association of Southeast Asian Nations (ASEAN) region. Asian Pac J Cancer Prev. 2014;15(19):8521-6.

7. Farmer P, Frenk J, Knaul FM, Shulman LN, Alleyne G, Armstrong L, Atun R, Blayney D, Chen L, Feachem R, et al. Expansion of cancer care and control in countries of low and middle income: a call to action. Lancet. 2010;376(9747):1186-93.

8. Yip CH, Samiei M, Cazap E, Rosenblatt E, Datta NR, Camacho R, Weller D, Pannarunothai S, Goh C, Black F, et al. Coordinating care and treatment for cancer patients. Asian Pac J Cancer Prev. 2012;13(4 Suppl):23-36.

9. Kimman $\mathrm{M}$, Jan $\mathrm{S}$, Kingston D, Monaghan $\mathrm{H}$, Sokha E, Thabrany $\mathrm{H}$, Bounxouei B, Bhoo-Pathy N, Khin M, Cristal-Luna G, et al. Socioeconomic impact of cancer in member countries of the Association of Southeast Asian Nations (ASEAN): the ACTION study protocol. Asian Pac J Cancer Prev. 2012;13(2):421-5.

10. Jan S, Kimman M, Peters SA, Woodward M. Financial catastrophe, treatment discontinuation and death associated with surgically operable cancer in South-East Asia: Results from the ACTION Study. Surgery. 2015;157(6):971-82.

11. The Action Study Group. Catastrophic health expenditure and 12-month mortality associated with cancer in Southeast Asia: results from a longitudinal study in eight countries. BMC Med. 2015;13:190.

12. Shi Q, Smith TG, Michonski JD, Stein KD, Kaw C, Cleeland CS. Symptom burden in cancer survivors 1 year after diagnosis: a report from the American Cancer Society's Studies of Cancer Survivors. Cancer. 2011;117(12):2779-90.

13. Wu HS, Harden JK. Symptom burden and quality of life in survivorship: a review of the literature. Cancer Nurs. 2015;38(1):E29-54.

14. Mitchell AJ, Chan M, Bhatti H, Halton M, Grassi L, Johansen C, Meader N. Prevalence of depression, anxiety, and adjustment disorder in oncological, haematological, and palliative-care settings: a meta-analysis of 94 interview-based studies. Lancet Oncol. 2011;12(2):160-74.

15. Pirl WF. Evidence report on the occurrence, assessment, and treatment of depression in cancer patients. J Natl Cancer Inst Monogr. 2004;32:32-9.

16. Stark DP, House A. Anxiety in cancer patients. Br J Cancer. 2000;83(10):1261-7.

17. Jones JM, Olson K, Catton P, Catton CN, Fleshner NE, Krzyzanowska MK, McCready DR, Wong RK, Jiang H, Howell D. Cancer-related fatigue and associated disability in post-treatment cancer survivors. J Cancer Surviv. 2016;10(1):51-61.

18. Minton O, Berger A, Barsevick A, Cramp F, Goedendorp M, Mitchell SA, Stone PC. Cancer-related fatigue and its impact on functioning. Cancer. 2013;119 Suppl 11:2124-30.

19. Ng CG, Mohamed S, See MH, Harun F, Dahlui M, Sulaiman AH, Zainal NZ, Taib NA. Anxiety, depression, perceived social support and quality of life in Malaysian breast cancer patients: a 1-year prospective study. Health Qual Life Outcomes. 2015;13:205.

20. Islam T, Dahlui M, Majid HA, Nahar AM, Mohd Taib NA, Su TT. Factors associated with return to work of breast cancer survivors: a systematic review. BMC Public Health. 2014:14 Suppl 3:S8.

21. Duijts SF, van Egmond MP, Spelten E, van Muijen P, Anema JR, van der Beek AJ. Physical and psychosocial problems in cancer survivors beyond return to work: a systematic review. Psychooncology. 2014;23(5):481-92.

22. Ganz PA, Yip CH, Gralow JR, Distelhorst SR, Albain KS, Andersen BL, Bevilacqua JL, de Azambuja E, El Saghir NS, Kaur R, et al. Supportive care after curative treatment for breast cancer (survivorship care): resource allocations in low- and middle-income countries. A Breast Health Global Initiative 2013 consensus statement. Breast. 2013;22(5):606-15.

23. Yip $\mathrm{CH}$, Taib NA. Challenges in the management of breast cancer in low- and middle-income countries. Future Oncol. 2012;8(12):1575-83.

24. Aaronson NK, Ahmedzai S, Bergman B, Bullinger M, Cull A, Duez NJ, Filiberti A, Flechtner H, Fleishman SB, de Haes JC, et al. The European Organization for Research and Treatment of Cancer QLQ-C30: a quality-of-life instrument for use in international clinical trials in oncology. J Natl Cancer Inst. 1993:85(5):365-76.

25. Fayers P, Aaronson N, Bjordal K, Sullivan M. EORTC QLQ-C30 Scoring Manual. EORTC Study Group on Quality of Life. Brussels: EORTC Data Center; 1995.

26. EuroQol Group. EuroQol-a new facility for the measurement of healthrelated quality of life. Health Policy. 1990;16(3):199-208.

27. Tongsiri S, Cairns J. Estimating population-based values for EQ-5D health states in Thailand. Value Health. 2011;14(8):1142-5.

28. Zigmond AS, Snaith RP. The hospital anxiety and depression scale. Acta Psychiatr Scand. 1983;67(6):361-70.

29. Bjelland I, Dahl AA, Haug TT, Neckelmann D. The validity of the Hospital Anxiety and Depression Scale. An updated literature review. J Psychosom Res. 2002;52(2):69-77.

30. World Health Organization. Management of Substance Abuse. Process of Translation and Adaptation of Instruments. http://www.who.int/substance abuse/research_tools/translation/en/. Accessed 10 Nov 2016.

31. Essue BM, Li Q, Hackett ML, Keay L, lezzi B, Tran KD, Tan Phuc H, Jan S. A multicenter prospective cohort study of quality of life and economic outcomes after cataract surgery in Vietnam: the VISIONARY study. Ophthalmology. 2014;121(11):2138-46.

32. Cocks K, King MT, Velikova G, de Castro JG, Martyn St-James M, Fayers PM, Brown JM. Evidence-based guidelines for interpreting change scores for the European Organisation for the Research and Treatment of Cancer Quality of Life Questionnaire Core 30. Eur J Cancer. 2012;48(11):1713-21.

33. Pickard AS, Neary MP, Cella D. Estimation of minimally important differences in EQ-5D utility and VAS scores in cancer. Health Qual Life Outcomes. 2007;5:70.

34. Cocks K, King MT, Velikova G, Martyn St-James M, Fayers PM, Brown JM. Evidence-based guidelines for determination of sample size and interpretation of the European Organisation for the Research and Treatment of Cancer Quality of Life Questionnaire Core 30. J Clin Oncol. 2011;29(1):89-96.

35. Rahman MM, Ahsan MA, Monalisa NN, Rahman K. Influence of socioeconomic status and BMI on the quality of life after mastectomy in Bangladeshi breast cancer patients in a public hospital. Jpn J Clin Oncol. 2014:44(12):1150-7.

36. Dunn J, Ng SK, Breitbart W, Aitken J, Youl P, Baade PD, Chambers SK. Health-related quality of life and life satisfaction in colorectal cancer survivors: trajectories of adjustment. Health Qual Life Outcomes. 2013;11:46. 
37. Zhou Y, Irwin ML, Ferrucci LM, McCorkle R, Ercolano EA, Li F, Stein K, Cartmel B. Health-related quality of life in ovarian cancer survivors: Results from the American Cancer Society's Study of Cancer Survivors - I. Gynecol Oncol. 2016;141(3):543-9.

38. Chambers SK, Meng X, Youl P, Aitken J, Dunn J, Baade P. A five-year prospective study of quality of life after colorectal cancer. Qual Life Res. 2012;21(9):1551-64.

39. Anderkova L, Elfmarkova N, Sverak T, Peterkova H, Brancikova D, Bendova M, Protivankova M, Benesova K, Dusek L, Jarkovsky J, et al. Change in quality of life measured over time in Czech women with breast cancer. Klin Onkol. 2016;29(2):113-21.

40. Jensen RE, Arora NK, Bellizzi KM, Rowland JH, Hamilton AS, Aziz NM, Potosky AL. Health-related quality of life among survivors of aggressive non-Hodgkin lymphoma. Cancer. 2013;119(3):672-80.

41. Vissers PA, Thong MS, Pouwer F, Zanders MM, Coebergh JW, van de Poll-Franse LV. The impact of comorbidity on health-related quality of life among cancer survivors: analyses of data from the PROFILES registry. J Cancer Surviv. 2013;7(4):602-13.

42. Wan GJ, Counte MA, Cella DF, Hernandez L, McGuire DB, Deasay S, Shiomoto G, Hahn EA. The impact of socio-cultural and clinical factors on health-related quality of life reports among Hispanic and African-American cancer patients. J Outcome Meas. 1999;3(3):200-15.

43. Ozturk A, Sarihan S, Ercan I, Karadag M. Evaluating quality of life and pulmonary function of long-term survivors of non-small cell lung cancer treated with radical or postoperative radiotherapy. Am J Clin Oncol. 2009;32(1):65-72.

44. Chang O, Choi EK, Kim IR, Nam SJ, Lee JE, Lee SK, Im YH, Park YH, Cho J. Association between socioeconomic status and altered appearance distress, body image, and quality of life among breast cancer patients. Asian Pac J Cancer Prev. 2014;15(20):8607-12.

45. Yan B, Yang LM, Hao LP, Yang C, Quan L, Wang LH, Wu Z, Li XP, Gao YT, Sun $Q$, et al. Determinants of quality of life for breast cancer patients in Shanghai, China. PloS One. 2016;11(4):e0153714.

46. Hoffman KE, McCarthy EP, Recklitis CJ, Ng AK. Psychological distress in longterm survivors of adult-onset cancer: results from a national survey. Arch Intern Med. 2009;169(14):1274-81.

47. Alfonsson S, Olsson E, Hursti T, Lundh MH, Johansson B. Socio-demographic and clinical variables associated with psychological distress 1 and 3 years after breast cancer diagnosis. Support Care Cancer. 2016;24(9):4017-23.

48. Niksic M, Rachet B, Warburton FG, Wardle J, Ramirez AJ, Forbes LJ. Cancer symptom awareness and barriers to symptomatic presentation in England-are we clear on cancer? Br J Cancer. 2015;113(3):533-42.

49. DiMartino LD, Birken SA, Mayer DK. The relationship between cancer survivors' socioeconomic status and reports of follow-up care discussions with providers. J Cancer Educ. 2016. Ahead of print.

50. Penson DF, Stoddard ML, Pasta DJ, Lubeck DP, Flanders SC, Litwin MS. The association between socioeconomic status, health insurance coverage, and quality of life in men with prostate cancer. J Clin Epidemiol. 2001;54(4):350-8.

51. Litwin MS, McGuigan KA, Shpall Al, Dhanani N. Recovery of health related quality of life in the year after radical prostatectomy: early experience. J Urol. 1999;161(2):515-9

52. Institute for Public Health. National Health and Morbidity Survey 1996: Recent IIIness/Injury, Health Seeking Behaviour and Out-of-pocket Health Care Expenditure. Kuala Lumpur: Ministry of Health; 1997.

53. Maters GA, Sanderman R, Kim AY, Coyne JC. Problems in cross-cultural use of the hospital anxiety and depression scale: "no butterflies in the desert". PLoS One. 2013;8(8):e70975.

54. Ginsberg GM, Lauer JA, Zelle S, Baeten S, Baltussen R. Cost effectiveness of strategies to combat breast, cervical, and colorectal cancer in sub-Saharan Africa and South East Asia: mathematical modelling study. BMJ. 2012;344:e614.

55. Myers ER, Moorman P, Gierisch JM, Havrilesky LJ, Grimm LJ, Ghate S, Davidson B, Mongtomery RC, Crowley MJ, McCrory DC, et al. Benefits and harms of breast cancer screening: a systematic review. JAMA. 2015;314(15):1615-34.

56. Distelhorst SR, Cleary JF, Ganz PA, Bese N, Camacho-Rodriguez R, Cardoso F, Ddungu H, Gralow JR, Yip CH, Anderson BO. Optimisation of the continuum of supportive and palliative care for patients with breast cancer in lowincome and middle-income countries: executive summary of the Breast Health Global Initiative, 2014. Lancet Oncol. 2015;16(3):e137-47.

57. Cheng KKF, Darshini Devi R, Wong WH, Koh C. Perceived symptoms and the supportive care needs of breast cancer survivors six months to five years post-treatment period. Eur J Oncol Nurs. 2014;18(1):3-9.
58. Payne S, Chan N, Davies A, Poon E, Connor S, Goh C. Supportive, palliative, and end-of-life care for patients with cancer in Asia: resource-stratified guidelines from the Asian Oncology Summit 2012. Lancet Oncol. 2012:13(11):e492-500.

59. Cleary J, Ddungu H, Distelhorst SR, Ripamonti C, Rodin GM, Bushnaq MA, Clegg-Lamptey JN, Connor SR, Diwani MB, Eniu A, et al. Supportive and palliative care for metastatic breast cancer: resource allocations in low- and middle-income countries. A Breast Health Global Initiative 2013 consensus statement. Breast. 2013;22(5):616-27.

60. Hershman DL, Ganz PA. Quality of care, including survivorship care plans. Adv Exp Med Biol. 2015;862:255-69.

\section{Submit your next manuscript to BioMed Central and we will help you at every step:}

- We accept pre-submission inquiries

- Our selector tool helps you to find the most relevant journal

- We provide round the clock customer support

- Convenient online submission

- Thorough peer review

- Inclusion in PubMed and all major indexing services

- Maximum visibility for your research

Submit your manuscript at www.biomedcentral.com/submit
) Biomed Central 